\title{
Editorial \\ Gray Materials in Dentistry: The Latin America Paradox
}

According with the US Food and Drug Administration (FDA), the term gray materials refers to dental or medical products sold outside an established distribution chain. Unlike black market products, gray materials are generally sold through legal channels, although these are not approved by the manufacturer, meaning they are unauthorized or unofficial. The American Dental Association, in conjunction with dental manufacturing companies, is leading an awareness campaign directed not only to dentists, but also patients. This campaign highlights the plausible risks of using these significantly cheaper materials.

The internet and online purchasing venues have provided easy opportunities for these products to enter any market. Additionally, there are no solid statistics on how frequently these materials are used worldwide, but it seems they could represent a greater threat to public health than we might think. The underlying problem of buying and using gray materials that are diverted from an authorized channel, is the uncertainty of their origin or transport, handling and storage conditions to which they were exposed. In some instances, the product might have been manufactured by the original company, but has been relabeled or repackaged. As an example, the gray material dealer might have bought more product than they could sell, and therefore try to sell it at a significant lower cost after its expiration date. Unfortunately, it is simple to mark the product's box with a fake expiration date. The unaware dentist will use the material on patients who could be harmed. Also, the longevity and effectiveness of the dental treatments might be compromised by these expired materials, putting at risk the dentist's reputation. An even bigger threat for the patient could be that the gray material actually is a counterfeit product. The packaging is a copy of the legitimate product, but the content is fake. In such cases, it could be difficult to identify.

Latin America is not excluded from this threat. For Latin American dentists, most of which work in developing economies, the opportunity to reduce costs and lower the price for dental treatments may seem very attractive. Consequently, these gray materials are commonly targeted to this region. Moreover, these countries' reduced import regulations, make it easier for gray products to enter the Latin markets. Products' quality or composition could somehow be altered in order to enter these markets at a lower cost. Also, the region is constantly exposed to materials produced locally, offering better prices than the original products. These materials may claim to be similar to the original, but most of them haven't undergone the necessary safety tests required in other world regions. There is a great need for these local materials to be properly analyzed, establishing safety parameters and clinical effectiveness before they are offered to the dental professionals, and eventually to the patients. This is significantly relevant as, in the end, dental professionals are responsible for guaranteeing the safety of the materials used on their patients.

\section{Mauricio Montero-Aguilar DDS, MSc}

Profesor-Investigador, Facultad de Odontología, Universidad de Costa Rica, Costa Rica. Correo electrónico: mauricio.monteroaguilar@ucr.ac.cr Tel: (506) 2511-8054

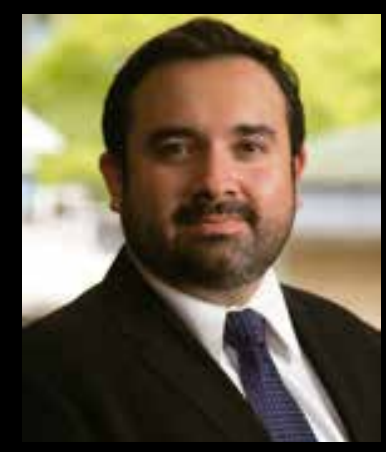

